\title{
Corrigendum
}

\section{Scheduling controllable processing time jobs in a deteriorating environment}

\section{Daniel Oron}

Business School, The University of Sydney, NSW, Australia

Journal of the Operational Research Society (2016) 67(3), 535. doi:10.1057/jors.2015.96

Published online 11 November 2015

Correction to: D. Oron (2014), Scheduling controllable processing time jobs in a deteriorating environment. Journal of the Operational Research Society doi:10.1057/jors.2013.5; 65(1), 49-56.

The author regrets two errors in the published paper:

1. On Page 52, Lemma 3: 'non-increasing order' should be 'non-decreasing order'.

2. On Page 55, Lemma 6: 'non-increasing order' should be 'non-decreasing order'.

The proofs are correct and consistent with the amended statements.

The author apologises for any inconvenience caused and would like to express his gratitude to Professor Lu Liu for pointing out these errors. 